\title{
SOCIETIES' MEETINGS.
}

\section{AMERICAN LARYNGOLOGICAL ASSOCIATION.}

May th $^{\text {th }}$ 1897. (Alstracted from "Med. Rec.," N.Y., May Sth, iSg7.)

\author{
Presilent-Ch.1s. II, KNIGHT.
}

The President delivered an address dealing'chiefly with the value of asepsis in clinical work; the value of the laryngoscope in relation to the singing voice; the Röntsen rays; and, finally; a most moderate riew of the need for vivisection.

Guatacol as an Anwsthetic in . Hinor (T)rations on the Nose ant Throat.

Dr. JAures E. Newcoun, New York City) read a paper with the above title. A five per cent. solution of the drug in olive oil is used whose resinoids and albuminoids are removed by dried sulphate of zinc and its fatty acids by alcohol. This is used in aural practice by instilling a few drops of the warm solution into the ear. In nasal surgery a soaked plug must remain in situ for from fifteen to twenty minutes. The greneral result of the author: investigations is that guaiacol is superior to cocaine when used on skin surfaces, but not equal to it on muccus surfaces.

Submucous Hemorrhage of the Vocal Corts. Dr. S. W. LAN(iMan, (Boston).

In all cases the situation of the rupture was at the junction of the middle and anterior thirds of the cord. Two of the patients were men and three women. All were of sudden origin, and were accompanied by hoarseness, vocal inability, and limitation of the higher register. Of the patients, four were singers and one an actor. The tumours were all globular, except one, which was diffuse. Treatment consists of rest, topical astringents, and tonics.

\section{Hysterical Dysphagia.}

Dr. A. Coolidge, jun. (Boston), read this paper. It had been noted by Hofmann in 1733. It seemed to occur about once in every five hundred cases at the Massachusetts General Hospital (nose and throat service). It was most frequent in women, but might occur in men and children. The onset was sudden, and might result from the temporary lodging of a foreign body in, the guilet, the symptoms being pain, a sense of constriction, and a feeling as of a foreign body. In addition to removal of any neighbouring lesions the passage of the sound was recommended.

In the discussion, Dr. T. HubBarD attributed it to saccular dilatation of the stomach. Dr. J. H. Lowman had cured a case by suggestion. Dr. GLeitsimann had cured a case by treating an anlarged lingual tonsil, Dr. Sw.1N agreeing with this as a usual cause. Drs. S. JoHNSTon and 
J. W. FARLOw had seen cases due to impaction of cerumen in the ear. Dr. EMIL MEYER had reported a case of congenital stenosis in a child. Dr. BRYSON DELAVAN believed some local lesion to be always present. Dr. LAINGMAID attributed the cause to anæmia. Dr. DALY referred to a case he had considered hysterical, where the patient died suddenly three days later.

Bacteria of the Normal Nose and Bactericidal Properties of Nasal Mucus. Drs. W. H. PARK and JONATHAN WRIGHT.

The works of previous investigators were first given, and then the observations of the speakers. Thirty-six normal noses were examined. The vibrissæ were removed by sterilized scissors, and the entrance to the nose washed with bichloride solution ; swab cultures from the interior were then made, thirty of these giving positive results. The nasal mucosa of two rabbits was found to contain bacteria. The mucus was inbihitory to anthrax. The scantiness of the microbes in the human nose might resuit from five causes. (I) Gravity - the fluids running down would clear away the micro-organisms ; (2) this is assisted by the cilia ; (3) the mucus was not a good culture medium for most bacteria ; $(4)$ the vibrissæ tended to keep the nose free ; (5) there are but few bacteria in ordinary tidal air. One drop of a virulent culture of bacteria was dropped into the nares of two rabbits, which both died on the second day.

The Treatment of Chronic Affections of the Tonsils. Dr. GLEITSMANN (New York).

The speaker dwelt upon the troubles caused by small tonsillar concretions, and upon the adherence of the tonsil tissue to the anterior pillar, and also on the occurrence of tonsillar flaps and folds. He then showed a punch working in an antero-posterior direction.

Dr. FARLOW also showed several tonsil hooks and forceps.

R. Lake.

THE LARYNGOLOGICAL SOCIETY OF LONDON.

Ordinary Meeting, May I2th, 1897.

Henry T. Burlin, Esq., F.R.C.S., President.

Discussion on the Uses of TURBInOtony as Applied to the INFERIOR TURBINATED BODY.

Opened by Dr. Dundas Grant.

TURBINOTOMY, or turbinectomy (perhaps better conchotomy or conchectomy), may be practised on the superior, middle, or inferior turbinated body, and it may be either total or partial. We might thus speak of total middle turbinectomy, total inferior turbinectomy, etc., or of anterior middle turbinectomy, posterior middle turbinectomy, and so forth. We are only concerned at present with the inferior turbinal and the operations of total inferior turbinectomy, anterior and posterior inferior turbinectomy 